\title{
O parco registro de desenhos industriais oriundos da moda em Pernambuco
}

\author{
The scarcity of industrial designs register that come from fashion in Pernambuco \\ El registro escasso de diseños industriales de moda em Pernambuco
}

Recebido: 23/09/2021 | Revisado: 29/09/2021 | Aceito: 01/10/2021 | Publicado: 04/10/2021

\author{
Pedro Henrique Sobral De Souza Azevedo Mayrinck \\ ORCID: https://orcid.org/0000-0002-7674-3156 \\ Universidade Federal de Pernambuco, Brasil \\ E-mail: pedrohsmayrinck@gmail.com \\ Danielle Silva Simões-Borgiani \\ ORCID: https://orcid.org/0000-0001-8995-9880 \\ Universidade Federal de Pernambuco, Brasil \\ E-mail: danielle.ssimoes@ufpe.br
}

\begin{abstract}
Resumo
Objetivo: Analisar a disseminação da proteção para desenhos industriais oriundos da prática profissional do designer de moda nas instituições que fomente empresas emergentes da economia criativa e na formação superior em Design e Design de Moda Pernambuco. Material e Métodos: delimitou-se a pesquisa como aplicada, qualitativa, exploratória, bibliográfica e documental. O recorte temporal foi dos últimos 5 anos $(2016-2020)$. Foram analisados projetos pedagógicos de 2 cursos superiores de Bacharelado em Design que possuíam disciplinas de moda e 5 Tecnologia em Design de Moda. Mapeou-se pontos profissionais de apoio/desenvolvimento de moda autoral e nestes, houve 5 eventos de disseminação de Propriedade Intelectual. Resultados: Há uma escassez de eventos que abordem proteção aos desenhos industriais para os ativos oriundos da moda autoral, e, ainda, ausência desse conteúdo na formação superior.
\end{abstract}

Palavras-chave: Inovação; Empreendedorismo; Propriedade intelectual; Desenho industrial; Design de moda.

\begin{abstract}
Objective: to analyse the dissemination of industrial designs protection that derives from the professional practices of the fashion designer in institutions that foster emerging companies of creative economy in the graduation of Design and Fashion design from Pernambuco. Materials and Methods: it was delimited as an applied, qualitative, exploratory, bibliographic and documental study. The time cutting was the last 5 years $(2016-2020)$. It was analysed 2 pedagogical projects of bachelor courses in Design that there are fashion disciplines and 5 Technological courses of Fashion design. It was shown professional points of support and development to original fashion brands and there were 5 events of dissemination of Intellectual Property. Results: there was a scarcity of events that address the protection of industrial designs asset to original fashion brands, and still the lack of these contents in graduation courses.
\end{abstract}

Keywords: Innovation; Entrepreneurship; Intellectual property; Industrial design; Fashion design.

\begin{abstract}
Resumen
Objetivo: Analizar la difusión de la protección de los diseños industriales derivada de la práctica profesional del diseñador de moda en instituciones que incentivan a las empresas emergentes en la economía creativa y en la educación superior en Diseño y Diseño de Moda Pernambuco. Material y métodos: la investigación se delimitó en aplicada, cualitativa, exploratoria, bibliográfica y documental. El período de tiempo fue para los últimos 5 años (2016 - 2020). Se analizaron los proyectos pedagógicos de 2 cursos de la Licenciatura en Diseño que contaban con disciplinas de moda y 5 de Tecnología de Diseño de Moda. Se mapearon puntos profesionales de apoyo / desarrollo de la moda autoral y en estos se realizaron 5 eventos para la difusión de la Propiedad Intelectual. Resultados: Existe una escasez de eventos que aborden los diseños industriales para los activos derivados de la moda de autor, y también la ausencia de este contenido en la educación superior.
\end{abstract}

Palabras clave: Innovación; Emprendimiento; Propiedad intelectual; Diseño industrial; Diseño de moda.

\section{Introdução}

Pernambuco é um estado de relevância econômica, além de ter destacada produção criativa e tecnológica no Brasil, com fortes investimentos na capacitação de empresas emergentes (Brasil, 2017). De modo semelhante, a região agreste possui visibilidade no cenário nacional na área têxtil e de confecções, garantindo voz ativa no mercado criativo da moda brasileiro. 
Para se manterem competitivas, as empresas devem inovar (Jungmann \& Bonetti, 2010) e este processo de inovação tange diretamente uma produção intelecto-criativa que é juridicamente protegida pela Propriedade Intelectual.

A Organização Mundial da Propriedade Intelectual (OMPI) dispõe que a Propriedade Intelectual pode ser compreendida como a soma de direitos, com forte influência de normas internacionais, em que há a proteção de bens incorpóreos, os quais podem ou não ter finalidade comercial. Barbosa (2017), acrescenta ao afirmar que é concepção do intelecto, exploração econômica da estética, um investimento em imagens ou em soluções técnicas de serviços e produtos. Cerqueira (1930) complementa que a Propriedade Intelectual se desdobra em dois ramos de direitos imateriais: os direitos do autor e a propriedade industrial.

Nesta pesquisa, a propriedade industrial, com recorte no desenho industrial foi a delimitação do estudo. Cerqueira (1930) define a propriedade industrial como o conjunto de normas e princípios jurídicos responsáveis pela proteção da produção intelectual no campo da indústria e pela repressão à concorrência desleal no comércio.

Dada a produção criativa da moda no estado e que tais criações intelectuais tem tutela jurídica própria, faz-se necessário analisar o desempenho dos desenhos industriais neste cenário. Ao observar os pedidos de registro no Instituto Nacional de Propriedade Industrial (2018), os números de Desenhos Industriais são muito aquém do pressuposto pelas qualidades criativas do país e da região.

Os desenhos industriais são espécies de propriedade intelectual destinados, conforme definição do Art. 95 da Lei no 9.279/96, à proteção legal da forma plástica ornamental de um objeto ou o conjunto ornamental de linhas e cores que possa ser aplicado a um produto, proporcionando resultado visual novo e original na sua configuração externa e que possa servir de tipo de fabricação industrial. Assim sendo, são os desenhos industriais capazes de abranger a tutela legal de grande segmento da produção criativa na moda autoral, de maneira a salvaguardar direitos essenciais aos seus titulares de preservarem-se moral e economicamente frente a terceiros.

A inobservância da proteção legal aos desenhos industriais pode acarretar sérios prejuízos. De ordem econômica, a empresa que negligencia a tutela jurídica de sua criação não consegue obter maiores proveitos econômicos, principalmente no ambiente externo, através de contratos de licença e cessão de direitos para terceiros, visto que tais criações ainda constituem bens da empresa, podendo ser negociadas conforme o planejamento dos seus ativos (Ramos \& Guterres, 2016).

De natureza moral, a omissão termina por estimular condutas de aproveitamento indevido do desenho industrial por terceiros, comportamentos tipificados e popularmente conhecidos por pirataria, desestimulando a produção criativa pela falta de reconhecimento ao seu titular, além de também pode acarretar sérios prejuízos e danos a marca. Tal problemática agrava-se quando empresas do mercado da moda que mantém destacada presença de profissionais de design, os quais trabalham diretamente com o desenvolvimento e concepção dos desenhos industriais, também sequer parecem mensurar a importância do respectivo ativo, ou desconhecendo-o, ou ignorando-o.

Diante desse cenário, delimitou-se como objetivo desta pesquisa investigar a formação em design buscando por conteúdos de Proteção Intelectual em relação aos ativos oriundos da prática profissional, e ainda se realizou um mapeamento de ações de disseminação de PI em instituições que fomentam empresas emergentes e inovadoras realizadas nos últimos 5 anos.

\section{Metodologia}

Tomando como referência Silva \& Menezes (2005) essa pesquisa é de natureza aplicada. Quanto a abordagem é qualitativa. Em relação aos objetivos é exploratória. Do ponto de vista dos procedimentos técnicos é bibliográfica (levantamento do referencial teórico e arcabouço da pesquisa) e documental (análise dos relatórios anuais do Instituto Nacional da Propriedade Industrial, Projetos Políticos Pedagógicos dos cursos de Design, Marco Regulatório da Inovação, relatório 
Políticas de Design e Proteção Intelectual - SEBRAE, entre outros).

Delimitação: (1) Da formação em design/design de moda - foram considerados os 5 cursos de formação superior em design de moda no estado de Pernambuco e 2 cursos de formação superior em design que ofertam disciplinas com conteúdo de moda. Esse recorte se deu, por considerar que podem ser oriundos destas formações os profissionais que estão proporcionando economia criativa com empresas de produtos da moda autoral. (2) Das ações de disseminação - foram mapeados 7 pontos profissionais de estímulo, apoio/fomento a empresas emergentes de economia criativa no recorte da moda autoral e nestes, buscou-se por eventos, ações, formações em Propriedade Intelectual com foco em Desenhos Industriais nos últimos 5 anos.

\section{Resultados e Discussão}

$\mathrm{Na}$ análise dos projetos políticos pedagógicos constatou-se inexistência de conteúdo ou disciplina sobre PI na formação. As estruturas curriculares apresentam muitas disciplinas de criatividade e algumas de inovação, mas não prevê em ementas como fazer a gestão e proteção dos ativos intelectuais da prática profissional do designer. Embora, na regulamentação do curso, nas Diretrizes Curriculares Nacionais (DCN), no Art. $4^{\circ}$ item VIII há uma abordagem da formação ofertar ao aluno visão consciente das "implicações econômicas, sociais, antropológicas, ambientais, estéticas e éticas de sua atividade” (Brasil, 2004). Uma vez que se preze por questões éticas na formação, entende-se que conhecimentos de proteção a PI deveriam fazer parte, pois além de servirem para proteger o criador, também resguardam de atos sem ética da prática, no tocante a plágio ou concorrência desleal promovidas por algum ativo concebido por um designer. Cabe trazer a esta discussão a reflexão de Simões-Borgiani (2021, p. 144) noutra pesquisa que contribui com a mesma perspectiva:

\footnotetext{
O designer passará a ter exercício pleno quando se formar com consciência ética e legal de sua prática. Sob que leis ele pode ter proteção, em que órgãos pode solicitar estes registros, como pode licenciar, ceder a titularidade ou receber royalties por seus ativos. Tanto se discute na formação a prática projetual, a criatividade e inovação, mas não se discute como tornar isso protegido. A proteção à propriedade intelectual favorece a concorrência leal, inovação, criatividade e competitividade. (Simões-Borgiani, 2021, p. 144).
}

Ainda no tocante a formação, Silveira, Nascimento \& Cardoso (2020) destacam que as discussões conceituais e legais sobre propriedade intelectual e inovação são de extrema importância e ao mesmo tempo que tem tantas possibilidades são pouquíssimos exploradas nas universidades, principalmente em relação ao comércio, indústria e sociedade.

Quanto as ações de disseminação, os pontos profissionais publicizaram sete eventos relacionados a proteção da propriedade intelectual. Convém destacar que tais eventos foram focados em assuntos bastante diversos desta área, porém, com enfoque particular para "marcas" (Tabela 1). Em momento algum é observado encontro, palestra ou qualquer sorte de episódio destinado a discutir especificadamente os desenhos industriais ou sequer os mencione dentro do conjunto de assuntos abordados na respectiva oportunidade.

Tabela 1. Eventos de disseminação de Propriedade intelectual realizados.

\begin{tabular}{|c|c|c|}
\hline Evento & Abordagem & Data \\
\hline Workshop de Propriedade Intelectual & $\begin{array}{l}\text { direitos do autor, registro de software, marcas, patentes, acordos de } \\
\text { confidencialidade, proteção de nome, imagem, som e licenças }\end{array}$ & 22 e 23 de julho de 2016 \\
\hline Semana da Propriedade Intelectual & Programa de Computador, Marca e Concorrência Desleal & 27 de abril de 2017 \\
\hline $\begin{array}{l}\text { Propaganda de Prestadora de Serviços de } \\
\text { PI aos associados }\end{array}$ & Não informado & 15 de janeiro de 2018 \\
\hline Reencontro ADG Brasil & Direitos Autorais & 17 de agosto de 2018 \\
\hline
\end{tabular}

Fonte: Autores. 
Diante da importância da matéria para os profissionais que comercializam produtos de moda autoral, são inquietantes o parco número de eventos que abordam a propriedade intelectual para Pernambuco neste segmento e como eles são dispersos entre, ocorrendo, nos cenários mais otimistas, um encontro por ano em cada ponto. Ainda mais alarmante é a total ausência na abordagem dos desenhos industriais para este público, visto que tutelam juridicamente grande parcela da produção criativa dos profissionais da moda.

Os resultados apontam a necessidade de políticas de disseminação de conteúdos de Propriedade Intelectual consistentes e sólidos, tanto na formação quanto nos agentes de fomento de empreendedorismo não bastando palestras ou consultorias pontuais para os empreendedores. Patrocínio (2013, 2018), o Grupo Interministerial da Propriedade Intelectual (2020), o Marco Regulatório da Inovação (Lei no 13.243/2016 - Marco Legal da Ciência, Tecnologia e Inovação) e a Estratégia Nacional de Ciência, Tecnologia e Inovação (2016-2022) apontam a necessidade em suas recomendações ou eixos estratégicos em disseminar PI para fomentar a inovação e economia do Estado e/ou País, no entanto, é preciso que as instituições de ensino e ou fomentadoras de empresas embrionárias com vistas da inovação se apropriem disto de forma eficiente.

Destaca-se ainda nesta discussão, que inclusive endossa o que vem sendo apontado da importância de aprimorar a disseminação de Propriedade Intelectual, uma vez que, mesmo com a pandemia do Covid-19, há uma expectativa promissora apontada no Índice Global de Inovação (UNIVERSIDADE CORNELL, INSEAD e OMPI, 2020), mas o Brasil ainda ocupa a posição 62 no índice, que termina na posição 131 com o Iêmen. Ainda há muito a percorrer, mas pequenas ações bem feitas, podem fazer a diferença.

\section{Considerações Finais}

Os achados contribuem para apontar a necessidade de políticas para aprimorar a disseminação de proteção ao desenho industrial tanto para designers de moda em formação quanto para empresas emergentes da área de moda autoral.

Compreende-se que seja necessária uma readequação dos projetos políticos pedagógicos na formação acadêmica dos designers a fim de aproximar os estudantes à matéria de Propriedade Intelectual. A compreensão desta matéria é fundamental para que os discentes desenvolvam, desde os estágios iniciais de sua aprendizagem, senso crítico ao produto de suas criações, pois, em virtude deste tipo de conhecimento, teriam noção de conceitos éticos a boas práticas concorrenciais.

A previsão de eventos consistentes e eficazes que discutam desenhos industriais é essencial para combater a apropriação indevida da destacada propriedade intelectual por terceiros, o que, no espectro micro, protege o titular de cópias ou demais atos de concorrência desleal previstos na Lei $n^{\circ}$ 9.279/96, e, no recorte macro, estimula a produção criativa e o consequente ganho econômico derivado desta no âmbito regional.

Além dos benefícios previstos aos profissionais e estudantes de design, bem como ao cenário econômico-criativo regional, a promoção e implementação de políticas públicas relativas à Propriedade Intelectual e, mais especificamente, a sua negligenciada espécie, os Desenhos Industriais, caminham na já existente tendência brasileira de promover a ações governamentais de inovação. Apesar da novidade na matéria de Inovação no país, o Brasil mantém uma agenda precária neste sentido ao promover de modo parco os Desenhos Industriais em ambientes de negócio e instituições públicas em geral, porém, com calculadas estratégias, é possível visualizar uma guinada positiva no cenário com a implementação de ações pontuais e de grande impacto social.

Esta pesquisa integra o grupo de pesquisa Design+, cadastrado no CNPq e tem aderência a linha Propriedade Intelectual e Inovação. Atualmente está em uma segunda fase na qual, estão sendo realizadas entrevistas com empresários de pequenos negócios de moda autoral pernambucana a fim de analisar o conhecimento e a experiência de empresas emergentes do mercado da moda em Pernambuco que possuem designers como gestores e/ou desenvolvedores de produtos autorais sobre a 
tutela jurídica de suas criações, os Desenhos Industriais, e dos proveitos econômicos e morais oriundos desta proteção.

\section{Nota}

Este artigo foi atualizado e adaptado do resumo originalmente debatido como no VII Congresso Internacional de Propriedade Intelectual, Gestão da Inovação e Desenvolvimento - Propriedade Intelectual, Inovações Disruptivas e Sustentabilidade. Simões-Borgiani, D. S. \& Mayrinck, P. H. S. S. A. (2021). Desenhos industriais e moda em Pernambuco: uma análise da formação de design e algumas ações de disseminação em propriedade intelectual no setor. In: Anais. VII Congresso Internacional de Propriedade Intelectual, Gestão da Inovação e Desenvolvimento - Propriedade Intelectual, Inovações Disruptivas e Sustentabilidade. IMED, Passo Fundo (on-line).

\section{Referências}

Barbosa, D. B. (2010). Uma Introdução À Propriedade Intelectual. (2a ed.), http://www.Denisbarbosa.Addr.Com/Arquivos/Livros/ Umaintro2.Pdf.

Barbosa, D. B. (2017). Tratado Da Propriedade Intelectual: Tomo I. (2a ed.), Lumen Juris.

Brasil. (2017). Governo De Pernambuco. Estratégia De Ciência, Tecnologia E Inovação Para Pernambuco. Secretaria De Ciência, Tecnologia E Inovação. Recife.

Brasil. (2020). Grupo Interministerial De Propriedade Intelectual (Gipi). Secretaria Executiva Do Gipi: Ministério Da Economia. Estratégia Nacional De Propriedade Intelectual. Brasília, 2020.

Brasil. (1996). Lei $N^{\circ}$ 9.279, De 14 De Maio De 1996. Regula Direitos E Obrigações Relativos À Propriedade Industrial. Brasília, 14 De Maio De 1996. Http://Www.Planalto.Gov.Br/Ccivil_03/Leis/L9279.Htm.

Brasil. (2004). Resolução $N^{o}$ 5, De 8 De Março De 2004. Aprova As Diretrizes Curriculares Nacionais Do Curso De Graduação Em Design E Dá Outras Providências. Brasilia, 8 De Mar,O De 2004. Http://Portal.Mec.Gov.Br/Cne/Arquivos/Pdf/Rces05_04.Pdf.

Brasil. (2016). Lei N 13.243, De 11 De Janeiro De 2016. Http://Www.Planalto.Gov.Br/Ccivil_03/_Ato2015-2018/2016/Lei/L13243.Htm.

Cerqueira, João Da Gama. (1930). Privilégios de Invenção e Marcas de Fábrica e de Commercio: Comentário ao Decreto N. 16.264, De 19 De Dezembro De 1923. São Paulo, Revista Dos Tribunaes.

Farias, L. L. N. De., Vasconcelos, C. B. De., Simões-Borgiani, D. S. \& Da Silva, J. B. P. (2021). Sondagem Com Designers Em Formação Sobre Conhecimento Do Registro De Marcas E Interferências Na Criação. In: Anais. XI PROSPECT\&I. V Congresso Internacional do PROFNIT - Autonomia Tecnológica, Produtiva e Sustentável.

Instituto Nacional Da Propriedade Industrial. (2018) Relatório De Atividades Inpi 2018. Http://Antigo.Inpi.Gov.Br/Noticias/Inpi-Divulga-Relatorio-DeAtividades-De-2018-No-Seu-Aniversario.

Jungmann, D. M. \& Bonetti, E. A. (2010). A Caminho Da Inovação: Proteção E Negócios Com Bens De Propriedade Intelectual: Guia Para O Empresário. Brasília: Iel, 2010.

Patrocínio, G. (2018). Políticas De Design E A Propriedade Intelectual: Demandas Para Uma Nova Era. Sebrae.

Patrocínio, G. (2013). The Impact Of European Design Polices And Their Implications In The Development Of A Framework To Support Future Brazilian Design Polices. Tese. Bedfordshire: Cranfield University

Ramos, A. S. C. \& Guterres, T. M. (2016). Lei Da Propriedade Industrial Comentada: Lei 9.279, De Maio De 1996.: Ed. Juspodvim.

Silva, E. L. Da \& Menezes, E. M. (2011). Metodologia Da Pesquisa E Elaboração De Dissertação. (4a ed.), Ufsc.

Silveira, C. F., Nascimento, J. B. do \& Cardoso, H. S. P. (2020). A theoretical-practical view of the diffusion of innovation and Intellectual Property. Research, Society and Development, 9(11), e71491110440. https://doi.org/10.33448/rsd-v9i11.10440.

Simões-Borgiani, D. S. (2021). A Formação Em Design E O Desconhecimento Da Proteção À Propriedade Intelectual. In: Barros, C. B. F., Marinho, C. T. Nascimento, B. R. Do. (Org). De(S)Colonizando O Design: Resumo Expandidos. Fortaleza: Editora Nadifúndio.

Simões-Borgiani, D. S., Mayrinck, P. H. S. S. A. (2021). Desenhos Industriais E Moda Em Pernambuco: Uma Análise Da Formação De Design E Algumas Ações De Disseminação Em Propriedade Intelectual No Setor. In: Anais. VII Congresso Internacional De Propriedade Intelectual, Gestão Da Inovação E Desenvolvimento - Propriedade Intelectual, Inovações Disruptivas E Sustentabilidade. Imed.

Universidade Cornell, Insead E Ompi (2020). Índice Global De Inovação 2020: Quem Financiará A Inovação? Ithaca, Fontainebleau E Genebra.

Vasconcelos, C. B. De., Simões-Borgiani, D. S., Mayrinck, P. H. S. D. S. A., De Amorim, C. R. F. (2021). Applied Study on Visual Identity Configuration Allied to Intellectual Property Protection In Pernambuco: Guidelines For Designers. International Journal of Advanced Engineering Research and Science, 8, 491-496. 